\title{
Erratum to: Do nuclear envelope and intranuclear proteins reorganize during mitosis to form an elastic, hydrogel-like spindle matrix?
}

\author{
Kristen M. Johansen • Arthur Forer • \\ Changfu Yao • Jack Girton · Jørgen Johansen
}

Published online: 15 May 2011

(C) Springer Science+Business Media B.V. 2011

\section{Erratum to: Chromosome Res \\ DOI 10.1007/s10577-011-9187-6}

The above mentioned article has been published in Chromosome Research, volume 19, issue 3, April 2011, pp. 345-365.

A Quicktime movie should have been published as Electronic Supplementary Material to complement figure 1 . The movie is referred to in the legend of figure 1 with the sentence 'The movie from which these images are derived is available in the Supplementary Material and was obtained as described in Ding et al. (2009). Scale bar $=10 \mu \mathrm{m}$ '.

The movie will be available to authorized users through the online version of this erratum.

The online version of the original article can be found at http:// dx.doi.org/10.1007/s10577-011-9187-6.

Electronic supplementary material The online version of this article (doi:10.1007/s10577-011-9217-4) contains

supplementary material, which is available to authorized users.

K. M. Johansen · C. Yao · J. Girton · J. Johansen $(\bowtie)$

Department of Biochemistry, Biophysics, and Molecular

Biology, Iowa State University,

3156 Molecular Biology Building,

Ames, IA 50011, USA

e-mail: jorgen@iastate.edu

A. Forer

Biology Department, York University,

Toronto, Ontario M3J 1P3, Canada 